\title{
Seasonal Prevalence of Gastrointestinal Nematodes of Goats in Pernambuco State, Brazil
}

\author{
T.P. CHARLES
}

Empresa Brasileira de Pesquisa Agropecuária (EMBRAPA-CPATSA), Cx. Postal 23, 56300 , Petrolina-PE (Brazil)

(Accepted for publication 28 March 1988)

\section{ABSTRACT}

Charles, T.P., 1989. Seasonal prevalence of gastrointestinal nematodes of goats in Pernambuco State, Brazil. Vet. Parasitol., 30: 335-343.

During each of 36 1-month periods from April 1979 to March 1982, 3-4 goats selected from typical farms were necropsied and examined for gastrointestial nematodes. The goats were male, 12 months old, born on the farm and raised without any anthelmintic application. At the beginning of each month, from April 1981 to Mach 1982, three 12-month-old male goats shown to be free of gastrointestinal nematodes after anthelmintic treatment were grazed with a flock of naturally infected goats (tracer goats). At the end of each month, these goats were placed on a cementfloored pen and were maintained there for 4 weeks prior to necropsy and examination for gastrointestinal nematodes.

Every goat examined was found to be parasitized by more than one species of nematode. Haemonchus contortus, Strongyloides papillosus and Oesophagostomum columbianum were the most prevalent nematodes found. Total worm burdens present in the farm animals were highest during late rainy/early dry season (March-June) and lowest in mid-rainy season (January-February). The acquisition of nematodes by tracer goats occurred mainly from mid-rainy to early dry season (January-June).

\section{INTRODUCTION}

Goats are an important source of food and income for small farmers in tropical areas of the world (Devendra, 1981). In Brazil, $90 \%$ of the goat population is concentrated in the semi-arid and arid areas of the north-east, where production is characterized mainly by a long post-partum interval, high mortality rate and low weaning (Guimarães Filho et al., 1982). Parasitic gastroenteritis is a common goat health problem in the region (Padilha, 1982).

Increased understanding of the biology and epidemiology of gastrointestinal parasites of cattle and sheep has lead to improvement in control measures and a decrease in production losses (Michel, 1985). However, little is known about 
parasitic gastroenteritis in goats. This paper presents the results of an investigation into the prevalence of gastrointestinal nematodes of goats in Pernambuco State, Brazil.

\section{MATERIALS AND METHODS}

\section{Study area}

The research was conducted in the Agricultural Research Center for SemiArid Tropical Regions (Centro de Pesquisa Agropecuária do Trópico SemiÁrido-Empresa Brasileira de Pesquisa Agropecuária), which is located at $\mathrm{Pe}$ trolina City in the State of Pernambuco, at latitude $09^{\circ} 05^{\prime} \mathrm{S}$, longitude $40^{\circ} 24^{\prime} \mathrm{W}$ and an elevation of $379 \mathrm{~m}$.

The vegetation in the study area, called caatinga, is a dense and diverse mixture of deciduous trees and shrubs and an annual herbaceous understory which lacks perennial grasses. The dominant species are carqueja (Caesalpinea depauperata), catingueira (Caesalpinea microphyla), faveleira (Cnidoscolus phyllacanthus), jurema (Mimosa nigra), quebra-faca (Croton sincorensis), angico (Piptademia macrocarpa), umbuzeiro (Spondea tuberosa), umburana (Bucera leptophlocos), barauna (Schinopsis brasiliensis), faxeiro (Pilosocereus glacensis), malva (Sida cordifolia), xique-xique (Palosocereus gournelli) and mandacaru (Cereus jamacaru).

The climate, characterized by distinct wet and dry seasons, is considered very arid according to Hargreaves' classification (Hargreaves, 1974). The av-

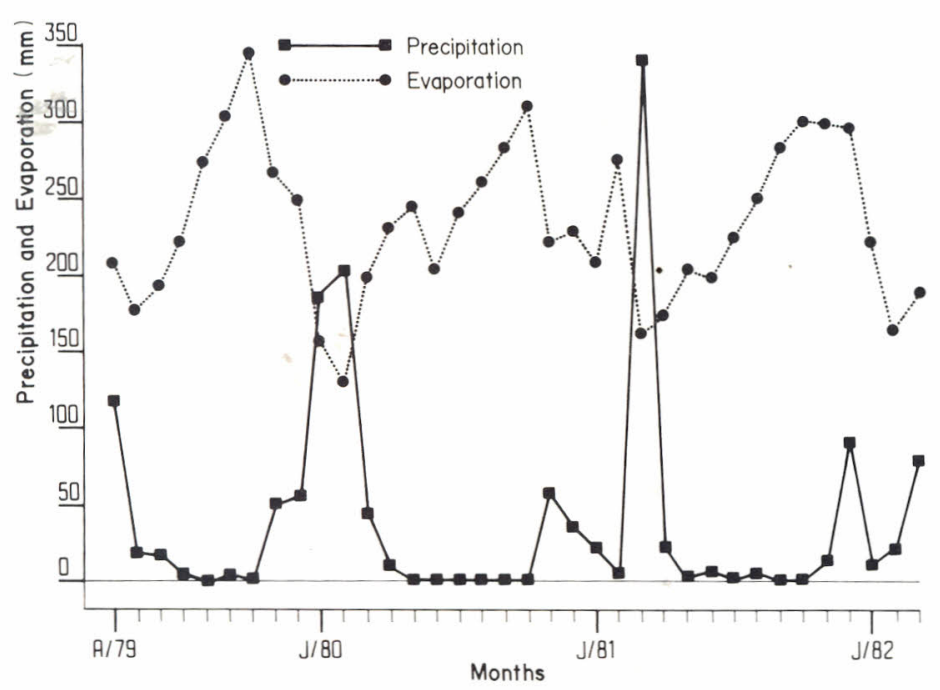

Fig. 1. Monthly mean evaporation and precipitation in millimeters, measured at Petrolina City, between April 1979 and March 1982. 


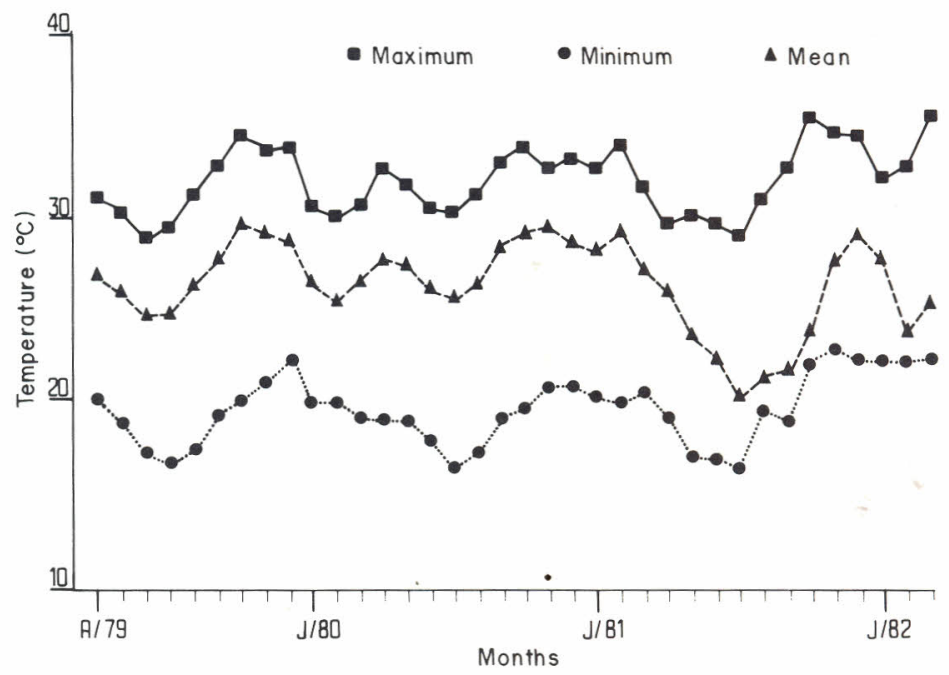

Fig. 2. Monthly means of minimum daily temperatures, mean daily temperatures and maximum daily temperatures, measured at Petrolina City, between April 1979 and March 1982.

erage annual rainfall of $350-400 \mathrm{~mm}$ is irregularly distributed between November and April. The dry season extends from May to October. There is little seasonal variation in temperature, which varies from a mean maximum of $28.5^{\circ} \mathrm{C}$ to a mean minimum of $24.0^{\circ} \mathrm{C}$. The average relative humidity is $55 \%$. Climatic data collected at the Metereologic Station located in the Experimental Station during the study period are shown in Figs. 1 and 2.

\section{Animal management}

The animals utilized were native SRD (sem raça definida, without definite race) goats, bred on farms typical of the region. The animals raised in this region are generally subjected to the following management regimen: every day the animals go to the native vegetation (caatinga) in the morning and return to the barn in the afternoon. The principal feed source is the natural vegetation. Towards the end of the dry season, the nutritive value of the vegetation declines to its lowest levels. The dry season imposes substantial nutritional stress on the animals and severe weight losses and deaths are common during this period. There are no supplementary feedings.

Most kids are born between March and May. Following birth, kids are kept in the corral for $\sim 30$ days, after which they go to the native pasture with their mothers. The animals are watered at a large, deep pond in which rainwater accumulates during the wet season. During the dry season, the drinking place gradually becomes dry. Generally, male animals are castrated after 12 months of age. The ratio between breeding males and females is generally 1:30. Goats 
are usually not milked and they are produced principally for meat and hides. Herd health management is not generally practiced. The farms lack perimeter fences, and cattle, sheep and goats use the same pasture at high stocking rates.

\section{Experiment 1}

Between April 1979 and March 1981, 12 -month-old male goats were chosen at random in the last week of each month from selected farms. Four neighboring farms, with management as described above, were selected to supply the animals because this region has a predominance of small herders and they could not have supplied all the necessary animals. Four animals were selected each month in the first 24 months and three were selected in the following 12 months. The animals were brought to the Experimental Station where they were killed and necropsied. Worms were collected and preserved for later identification.

\section{Experiment 2}

Between March 1981 and February 1982, three 12-month-old male goats were chosen each month at the farms described for use as tracer goats. They were taken to the Experimental Station and placed in a cement-floored pen for 4 weeks. To remove existing helminth infections, goats were dosed on arrival with fenbendazole $\left(7.5 \mathrm{mg} \mathrm{kg} \mathrm{kg}^{-1}\right)$ and levamisole $\left(12 \mathrm{mg} \mathrm{kg}^{-1}\right)$ at 7 and 14 days after arrival. Feces were examined weekly using the Wisconsin Sugar Flotation procedure and no animals were found to be positive after the first treatment. Six animals submitted to this treatment were necropsied to evaluate the efficacy of anthelmintic treatment and were found to be worm-free.

At the beginning of the first week of each month between April 1981 and March 1982, three tracer goats were placed with a flock of infected goats. The goat flock, composed of 30 adult females, their kids and one male, was confined in a fenced 75-ha area of native vegetation. The flock had been in this enclosure since November 1977 and had not received anthelmintic treatment since that time. At the end of each month, the three tracer goats were returned to the cement-floored pen; they were maintained there for 4 weeks and were then necropsied.

\section{Parasitological methods}

At necropsy, gastrointestinal tracts were removed and transported to the laboratory for examination. Abomasa, small intestines and large intestines were ligated to prevent worms from spilling from one location to another. In the laboratory, each organ was opened separately and the mucosa washed in water to remove all parasites. Abomasal and intestinal contents were washed through 
wire mesh of $37-\mu \mathrm{m}$ aperture, those of the large intestines were washed through wire mesh of $105-\mu \mathrm{m}$ aperture. The remaining material was preserved with formalin $10 \%$ and examined at a later date. For counts of worms recovered from the abomasa and small intestines, the total contents were first diluted to a volume of $2 \mathrm{l}$ and an initial aliquot of $10 \%$ of the total volume was counted. If this initial aliquot contained $<100$ worms, another $10 \%$ aliquot was examined. Samples which contained few worms were counted completely. Total counts were made for each large intestine examined. Every nematode recovered was clarified in lactophenol and mounted on a microscope slide for identification.

The abomasal and small intestinal mucosae were soaked in saline at $37^{\circ} \mathrm{C}$ for $2 \mathrm{~h}$. After soaking, the mucosa was washed and the washings added to the saline, and the mixture washed through a $37-\mu \mathrm{m}$ wire mesh under tap water. The residue retained on the wire mesh was preserved with $10 \%$ formalin and examined at a later time.

\section{RESULTS}

\section{Experiment 1}

Every goat examined was infected by more than one species of nematode. Haemonchus contortus, Strongyloides papillosus and Oesophagostomum columbianum were the most prevalent species in the abomasum, small intestine and large intestine, respectively. The species of worms found and their prevalences, ranges, mean worm burdens and host sites are presented in Table 1. Bunostomum trigonocephalum occurred in only one animal in which two female worms were recovered in March, 1980.

The mean numbers of worms collected exceeded 1000 nematodes per goat in most of the study months. Peaks of total worm burden were observed in June

\section{TABLE 1}

Species, prevalence and range of gastrointestinal nematodes found in 132 goats from Petrolina City

\begin{tabular}{llllr}
\hline Organ & Species & $\begin{array}{l}\text { Prevalence } \\
(\%)\end{array}$ & Range & $\begin{array}{l}\text { Mean worm } \\
\text { burdens }\end{array}$ \\
\hline Abomasum & Haemonchus contortus & 96.9 & $1-2045$ & 365 \\
& Trichostrongylus axei & 74.1 & $2-430$ & 51 \\
Small intestine & Strongyloides papillosus & 95.4 & $2-2351$ & 524 \\
& Trichostrongylus colubriformis & 74.1 & $1-1360$ & 58 \\
Large intestine & Oesophagostomum columbianum & 87.0 & $1-281$ & 51 \\
& Trichuris ovis & 44.3 & $1-154$ & 8 \\
& Skrjabinema ovis & 40.5 & $1-1480$ & 90 \\
\hline
\end{tabular}



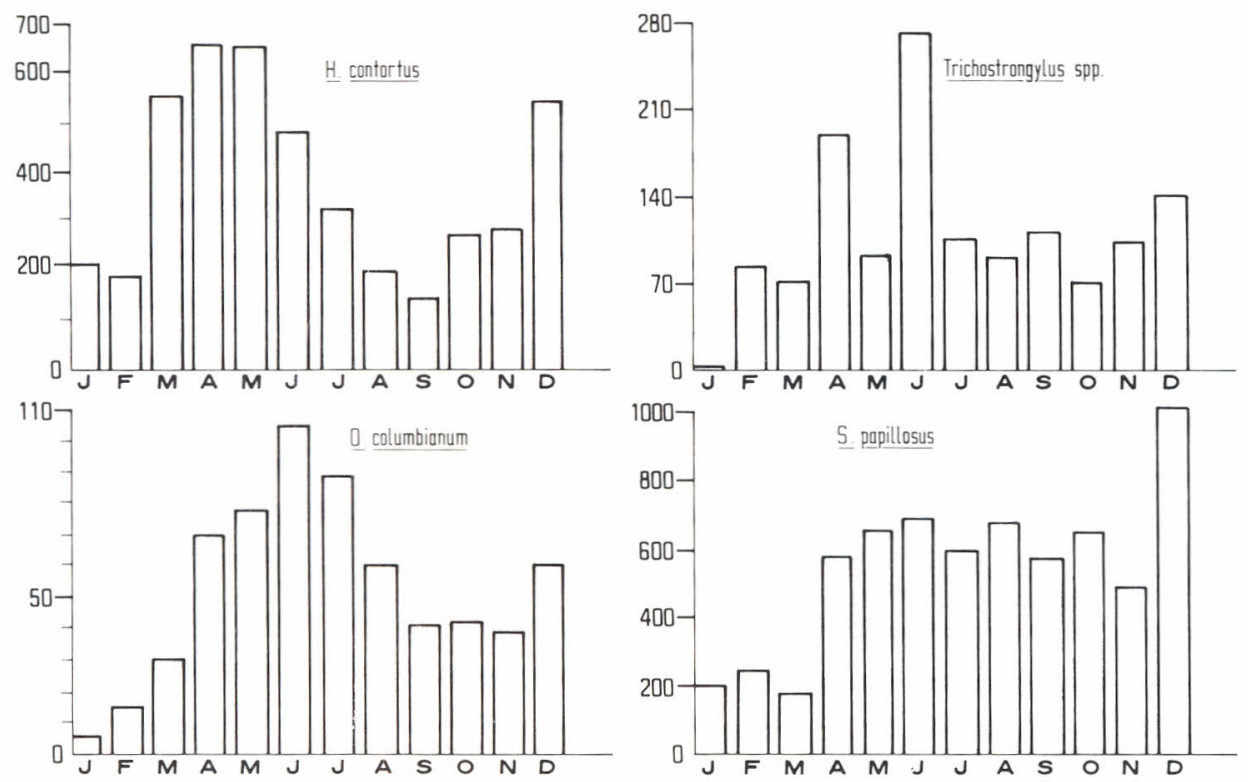

Fig. 3. Means of monthly counts of $H$. contortus, Trichostrongylus spp., O. columbianum and S. papillosus between April 1979 and March 1982 (Experiment 1).

TABLE 2

Total numbers of gastrointestinal nematodes and total $H$. contortus acquired by tracer goats

\begin{tabular}{lrr}
\hline Month of grazing & Total worms & H. contortus \\
\hline April 1981 & 162 & 88 \\
May & 88 & 46 \\
June & 33 & 11 \\
July & 2 & 0 \\
August & 4 & 0 \\
September & 16 & 0 \\
October & 4 & 0 \\
November & 9 & 0 \\
December & 7 & 1 \\
January 1982 & 21 & 11 \\
February & 60 & 50 \\
March & 52 & 42 \\
\hline
\end{tabular}

1979, December 1979, March 1980 and December 1981. H. contortus burdens increased in December, declined in January-February, increased again from March to June and declined as the dry season progressed. Mean numbers of H. contortus, Trichostrongylus spp. (T. axei and T. colubriformis), S. papillosus and $O$. columbianum collected in different months of the year are shown in Fig. 3. 
Experiment 2

Transmission of gastrointestinal nematodes, as detected by tracer goats, occurred mainly from February to May. The numbers of worms acquired by tracers are presented in Table 2.

No fourth stage larvae of any species were observed in any examined animal.

\section{DISCUSSION}

The species of gastrointestinal nematodes found in these experiments were generally similar to those reported in north-east Brazil (Costa, 1980). H. contortus, S. papillosus and O. columbianum, the most prevalent species found in the abomasum, small intestine and large intestine, respectively (Table 1 ), were also highly prevalent in previous studies in Pernambuco State and other regions of north-east Brazil (Costa, 1980).

Although $100 \%$ of the goats were infected, their worm burdens (Table 2, Fig. 3 ) were not high. Similar worm burdens were found in goats in other arid and semi-arid regions of north-east Brazil and elsewhere (Abdul-Quadir, 1967; Fabiyi, 1970; Travassos et al., 1974; Cavalcanti, 1974; Girão et al., 1980). Clinical gastroenteritis in the region usually occurs during the wet season and in the early portion of the dry season (Padilha, 1982). It appears that a low worm burden could be of pathogenic significance in arid and semi-arid regions.

Burdens of $H$. contortus dropped in January and February (Fig. 3). Self-cure phenomenon, as described in sheep of the semi-arid areas of Kenya (Allonby and Urquhart, 1973), or better nutrition which enhanced the animals' immunity could be the reason for this decrease in $H$. contortus loads.

Although no transmission of gastrointestinal nematodes was observed in tracer goats in dry months (Table 2), animals selected from the farm harbored adult worms of all species (Fig. 3). The worms found in these animals could have originated from infections acquired in the late rainy/early dry season or from larvae resuming development after a period of hypobiosis.

The low burdens acquired by tracer goats (Table 2) may have been due to the low stocking rates in which they were maintained or to acquired immunity. Higher worm burdens have been observed in goats maintained at higher stocking rates (le Jambre, 1984). Because the tracers used in these experiments were animals which may have had previous infections with gastrointestinal nematodes, acquired immunity may have played some role in preventing them from developing a higher burden of worms.

No recovery of fourth stage larvae in the mucosae or contents of the abomasa and small intestines of the examined animals was unexpected. Connan (1975) stated that peptic digestion is not necessary for the recovery of inhibited larvae of $H$. contortus in sheep; these larvae can be liberated by a 30 -min soak in warm water. However, recovery of hypobiotic larvae of Ostertagia ostertagi from cat- 
tle is best obtained by peptic digestion (Kingsley and Gerber, 1984). Our findings suggest that a 2 -h soak of goat abomasal mucosa may not be long enough to liberate larvae and that peptic digestion may be necessary. Since the worm loads of the animals were low, we suggest that fourth stage larvae were also present only in low numbers in mucosae and contents and that these larvae, therefore, could have easily been missed during collection and examination of the material.

\section{ACKNOWLEDGEMENTS}

The author thanks Silverio Hipolito and Daniel B. de Miranda for their valuable technical assistance. This work was supported by a grant from EMBRAPA-CPATSA (Centro de Pesquisa Agropecuária do Trópico Semi-Árido) Cx. Postal 23, 56 300, Petrolina, PE, Brazil.

\section{REFERENCES}

Abdul-Quadir, A.N.M., 1967. Investigation on the incidence of gastrointestinal parasites of the goats in the East Pakistan Agricultural campus. Ceylon Vet. J., 15: 58-61.

Allonby, E.W. and Urquhart, G.M., 1973. Self-cure of Haemonchus contortus infection under field conditions. Parasitology, 66: 43-53.

Cavalcanti, A.M.L., 1974. Prevalencia estacional de helmintos gastrointestinais de caprinos nas zonas da mata, agreste e do sertão. M.S. Thesis, Universidade Federal de Minas Gerais, Belo Horizonte, $48 \mathrm{pp}$.

Connan, R.M., 1975. Inhibited development in Haemonchus contortus. Parasitology, 71: 239-246.

Costa, C.A.F., 1980. Helmintoses de caprinos e ovinos: Estágio actual da pesquisa no Nordeste brasileiro. In: H.J.H. Melo (Editor), Anais do II Seminário Brasileiro de Parasitologia Veterinária. EMBRAPA, Brasilia, pp. 41-58.

Devendra, C., 1981. Potential of sheep and goats in less developed countries. J. Anim. Sci., 51: 461-473.

Fabiyi, J.P., 1970. An investigation in to the incidence of goat helminth parasites in Zaria area of Nigeria. Bull. Epizoot. Dis. Afr., 18: 29-34.

Girão, E.S., Girão, R.N. and Medeiros, L.P., 1980. Prevalencia e variação estacional de helmintos gastrointestinais de caprinos no municipio de Valença do Piauí, EMBRAPA-UEPAE Teresina, $\mathrm{Pl}$, Pesquisa em andamento, O1, 5 pp.

Guimarães Filho, C., Soares, J.G.G. and Albuquerque, S.G., 1982. Desempenho de caprinos criados extensivamente em areas de caatinga não cercada. EMBRAPA-CPATSA, Petrolina, PE, Boletim de Pesquisa 17, 24 pp.

Hargreaves, G., 1974. Climatic zoning for agricultural production in Northeast Brazil. Utah State University, Logan, 5 pp.

Kingsley, C.C. and Gerber, H., 1984. Retrieval of nematode larvae. Vet. Rec., 115: 334.

Le Jambre, L.F., 1984. Stocking rate on the worm burdens of Angora goats and Merino sheep. Aust. Vet. J., 61: 280-282.

Michel, J.F., 1985. Epidemiology and control of gastrointestinal helminths in domestic animals. In: H. Vanden Bossche, D. Thienport and P.G. Janssens (Editors), Chemotherapy of gastrointestinal Helminths. Springer-Verlag, Berlin, Heidelberg, pp. 67-123. 
Padilha, T.N., 1982. Doenças parasitárias em caprinos nas regiões áridas e semi-áridas no Nordeste brasileiro. EMBRAPA-CPATSA, Petrolina, PE, Documentos 17, 46 pp.

Travassos, T.E., Pereira, I.H., Tavares, H.P. and Leite, A.C.R., 1974. Epizootiologia das helmintoses caprinas no Sertão de Pernambuco. In: Centro de Pesquisas Zoopatológicas, Recife, PE, Relatório de Atividades, p. 89. 